will be termed $\sigma$. Equation (1) may be written $\varphi_{ \pm}=\sigma \pm 2 \rho$, where $\rho$ is the bend of the circle inscribed in the triangle formed by joining the centres of the trio. $\varphi_{+}+\varphi_{-}=2 \sigma$.

But if the fourth sphere has any other value, say $\delta$, between the maximum and minimum, the centres are no longer co-planar, but four bends being fixed, the fifth is determined by and can be found from the quadratic equation for five spheres in mutual contact (ibid., verse 3 ).

$3\left(\varphi^{2}+\alpha^{2}+\beta^{2}+\gamma^{2}+\delta^{2}\right)=(\varphi+\alpha+\beta+\gamma+\delta)^{2}$ or $\varphi \pm=\frac{1}{2}[\alpha+\beta+\gamma+\delta \pm\{6(\alpha \beta+\alpha \gamma+\alpha \delta+$ $\left.\left.\beta \gamma+\beta \delta+\gamma \delta)-3\left(\alpha^{2}+\beta^{2}+\gamma^{2}+\delta^{2}\right)\right\}^{1 / 2}\right]$

As always, we get two real roots, which refer, not to opposite beads of the hexlet as in the two-dimensional equation, but to the two on either side of the one to which the bend, $\delta$, has been assigned. Hence we have

$\varphi_{+}+\varphi_{-}=\sigma+\delta$; or $\varphi_{N+1}+\varphi_{N-1}=\sigma+\varphi_{N}$; or $\varphi_{3}=\sigma+\varphi_{2}-\varphi_{1}$,

where $\varphi_{N+1}, \varphi_{N}$ and $\varphi_{N-1}$ refer to the bends of any three consecutive beads. From this, any two consecutive beads being known, all the others can be written down at once, when it will be found, quite unexpectedly I think, that this simple relation conceals a periodic function, with a perjod of six, or $\varphi_{N+6}$ $=\varphi_{N}$. Thus the six beads have values, in terms of those of any two consecutive beads, $\varphi_{1}$ and $\varphi_{2}$, (1) $\varphi_{1}$; (2) $\varphi_{2}$; (3) $\varphi_{3}=\sigma+\varphi_{2}-\varphi_{1}$; (4) $\varphi_{4}=\sigma+\varphi_{3}-\varphi_{2}=2 \sigma$ $-\varphi_{1}$; (5) $\varphi_{5}=\sigma+\varphi_{4}-\varphi_{3}=2 \sigma-\varphi_{2}$; (6) $\varphi_{8}=\sigma+$ $\varphi_{5}-\varphi_{4}=\sigma+\varphi_{1}-\varphi_{2} ;(7) \varphi_{7}=\sigma+\varphi_{6}-\varphi_{5}=\varphi_{1}$.

It will be seen that the sum of the bends of each opposite pair remains constant at $2 \sigma$, though any value $\delta$ between limits was given to the one bend arbitrarily fixed. The hexlet in fact is free to revolve round the trio without loss of serial contact, or separation of its several beads each from contact with all three of the trio. Similarly any given hexlet may be fixed and the trio varied through a definite cycle in which $\sigma$ remains unchanged but the three individual bends vary interdependently.
The primary hexlet of the bowl of integers is free to revolve in its tri-spherically sided annulus without change of grade, because exceptionally all its beads are identical, and this property is not due to two of the spheres of the trio being equal, but derives from the sum of their radii being equal to that of the bowl. Using Roman letters for radii, $A$ and $B$ may have any values so long as they sum to $C$, or using Greek letters for bends, so long as $1 / \alpha+1 / \beta+1 / \gamma=0$. When we introduce this value for $\gamma$ into the surd of equation (I) for four circles in mutual contact $\alpha \beta+\alpha \gamma+\beta \gamma$, it vanishes and $\varphi_{+}=\varphi_{-}=\sigma$. When we introduce these values for $\gamma$ and $\delta, \delta$ being the $\varphi$ of equation (1) when $\varphi_{+}=\varphi_{-}$, into equation (2), its surd

$$
\begin{aligned}
& 6(\alpha \beta+\alpha \gamma+\alpha \delta+\beta \gamma+\beta \delta+\gamma \delta)-3\left(\alpha^{2}+\beta^{2}+\right. \\
& \left.\gamma^{2}+\delta^{2}\right), \text { or }(\varphi+-\varphi-)^{2},
\end{aligned}
$$

also becomes zero, and $\varphi_{+}=\varphi_{-}$. That involves that all the six spheres of the hexlet are identical, because the opposite members as well as those on each side of them are all equal.

In conclusion, one point of really fascinating historical interest emerges. The Greeks, in their study of the $\alpha \rho \beta \eta \lambda \circ \varsigma$ or "shoemaker's knife", obtained by pure geometry the radius of the fourth circle that will make mutual contact with a mutually tangent trio for which $A+B=C$, whatever the ratio $A: B$. The proposition from the Arabic "Liber Assumptorum" will be found in full with notes in Sir Thomas Heath's "Works of Archimedes", p. 307 (Camb. Univ. Press, 1897). In the actual figure by which the proof was demonstrated $A / B$ was $3 / 2$, which gives for the radius in question $6 / 19$, in terms of $C$ as unity, when, therefore, $A$ is $3 / 5$ and $B$ is $2 / 5$. Since $\varphi=\sigma$,

$$
\varphi=5 / 3+5 / 2-1=19 / 6 !
$$

It is curious this should have remained unnoticed for thousands of years. Possibly when a mental arithmetic of reciprocals becomes as natural as that of number we may hope to learn the real secret of the circle and the sphere.

\title{
Climatic Discomfort
}

$\mathrm{M}^{\mathrm{s}}$ R. W. F. TYLER, an engineer interested in meteorology, was led to make an investigation into the connexion between climatic discomfort and the state of the atmosphere in regard to temperature and humidity. A summary of his work is to be found in a reprint of a paper read before Section $J$ (Psychology) of the British Association at Blackpool.

Mr. Tyler began his work at Shanghai more than thirty years ago. He was helped by the late Father Froc, then director of Siccawei Observatory, Shanghai, and by twelve observers-well-educated, intelligent men, one gathers-who during the month of August 1902 made an observation at every noon of their sensation of discomfort from the heat and dampness while sitting quietly in their offices, cooled by the punkah or fan to which they were accustomed. Their sensations were recorded on an arbitrary scale extending from I to 10 ; the numbers on the scale have been called hythers, hyther 10 being taken to represent an "unbearable condition". As the result of these determinations we have a very interesting diagram in which the hythers are shown as sloping, nearly parallel, slightly curved lines derived from plottings of the individual observations with temperatures as abscissæ and the differences between the dry and wet bulb thermometers as ordinates. The course of each hyther shows how much change in the depression of the wet bulb was required on an average to prevent any given change of temperature from altering the discomfort appropriate to that hyther.

One is tempted to criticize this fundamental diagram, on which a number of climatic studies have been based, on the grounds that the data are too meagre, that one individual differs greatly from another in response to atmospheric conditions, and that each varies according to health, state of mind and other influences, but Mr. Tyler surely deserves credit for trying to bring more precision into the psychology of hot climates, and his work should be 
of practical value in problems of air conditioning in such climates. Hythers suitable for temperate climates might be useful to European weather forecasters in more scientific times in the future, when air temperature and discomfort may be forecast separately. The general public does not know that in present-day forecasts the forecaster's references to temperature apply to temperature recorded in a screen designed to remove the vitally important effects of radiation. This fact results often in the anomaly of the forecaster knowing that he has made a technically correct forecast while even intelligent readers of the forecast imagine that it has gone utterly astray. But the hyther system would be more likely to give useful results in the near future in the comparison of different climates with very large contrasts of temperature and humidity.

The usefulness of a scale of discomfort of the type used by Mr. Tyler is apparent from a recent article entitled "Temperature Profiles in Toronto" by W. I:. Knowles Middleton and F. Graham Millar ( $J$. Roy. Ast. Soc. Canada, Sept. 1936). It is an account of observations of air temperature made with a nickel resistance thermometer of small lag, well shielded from radiation, which was mounted two feet from the front of a car 27 inches above the road. The observations were made in a street that runs north. north-west from the shore of Lake Ontario to the northerm limit of the town of Toronto and continues as a paved highway several miles farther in the same direction. Observations of this kind, it may be noted, were made by $\mathrm{H}$. Tollner in Vienna in 1931 (Sitz. Akar. Wiss. Wien, Math. Nat. Kl., Abt. $\mathrm{II}_{\mathrm{a}}, 141$, $1-13 ; 1932$ ). The results of a few selected sets of observations are discussed. 'They are shown as graphs with temperature as ordinates and distances from the lake as abscissw. The elevation of the land is also plotted, so that temperature variations can be related at a glance to the changes of elevation. On a hot sunny day with light southerly wind, a very sharp rise of temperature was observed in the first 200 yards from the lake front and then an average increase of $1 \cdot 3 \mathrm{k}$. in each mile for five miles, after which temperature fell a few degrees in the more countrified surroundings. At such times workers in offices near the lake have the advantage in tem. perature but expcrience a higher humidity and dew point as compared with their families in the residential parts higher up and farther from the lake. In the absence of a sensitive seale of climatic discomfort on the lines of the scalc obtained by Tyler, it is difficult to form an jelea as to which of the two is the better off. Another graph for a clear winter night showed a difference of no less than $27^{\circ} \mathrm{F}$. between the botiom of a valley and its crist, for a difforencer of hright of about 120 feet.

\section{Chemistry of Essential Oils}

$\mathrm{I}^{\mathrm{N}}$ the nincteenth Streatfoild Memorial Lecture, delivered at the Institute of Chemistry on November 20, Prof. John Read, of the University of St. Andrews, described a chapter in organic chemistry of extraordinary fascination. $\mathrm{He}_{\mathrm{e}}$ showed how the discovery by Captain Cook of Australia opened a new field of research in the related sciences of botany and chemistry, which was soon appreciated by the early settlers in that continent.

Dr. John White, Surgeon-General to the first settlement at Botany Bay under Governor Phillip, and First Assistant Surgeon D. Considen, both referred in or about 1788 to a large peppermint tree growing around Port Jackson, the essential oil of which bore a close resemblance to that obtained from peppermint (Mentha piperita) long grown in England. This Australian tree, now known as Eucalyptus piperita. or the Sydney peppermint, was supposed to contain the same odoriferous constituent, menthone, as the English tree. But in 1900 this peppermint odour of the genus Eucalyptus was shown by H. G. Smith to be a distinct ketone to which he gave the appro. priate name of piperitone.

Prof. Read compared Smith with Streatfeild as regards his Kentish origin and his unselfish devotion to practical organic chemistry. Migrating to Sydnoy for reasons of health, Smith took up the study of chemistry and devoted himself especially to tho chemistry of the Australian flora. His most remarkable work on the chemical nature of the essential oils of the genus Eucalyptus, which includes three hundred species, has an important bearing on the development of the natural resources of Australia. Certain oils were found to be rich in cineole, phell. andrene, geraniol, citral, pinene and piperitone, whorcas others yichled now chenical constituents peculiar to the Australian flora. Some of these researchos werc rarried out in collaboration with Profs. Read and J. (. Earl, both of whom were former pupils of streatfoikt.

Piperitone, which is a key to the stereochemistry of the menthones, menthols and related substances, is invariably lovorotatory when obtained from encalyptis, whereas from a Himalayan grass Andro. pogon Jwarancusa it was isolated by Simonsen in tho dextrorotatory varisty (1921).

Prof. Tread then showed how the systematic study of tho piperitones as pursued at St. Andrews has disclosod a now approach to the menthols and their congeners. These storeochemical researches offer a clue to the biogenetic relationships of the constituents of essential oils, some of which were traced by Smith and his co-workers. According to J3aker and Smith, the open chain, geranyl acctate, passed into Eucalyptus through Angophorc (an Australian genus of Myrtaceæ) and probably runs through the whole of the oucalypts although sometimes present only in small amounts.

In most species of eucalypts, geraniol may be presumed to finction as the precursor of $l$-piperitol, $l$-piperitone, $\alpha$-phellandrene and allied substances. The delicato control of molccular mochanism takes, however, a different turn in the Indian grasses, where geraniol becomes transformed into the enantiomeric $d$-piperitol, $d$-piperitone and into $\Delta^{4}$-carene. In the present stage of knowledge these subtle differentiations are beyond the powers of the chemical laboratory and appear to be inseparably bound up with vital processes. 'The systrmatic study of these biochemical phenomena is of wide seientific interest and also of considerable industrial significanee.
G. T.M. 